\title{
A TRANSMISSÃO DOS CONHECIMENTOS PRODUZIDOS POR PROGRAMAS DE PÓS-GRADUAÇÃO INTERDISCIPLINARES
}

THE TRANSMISSION OF KNOWLEDGE PRODUCED BY INTERDISCIPLINARY GRADUATE PROGRAMS

\section{LA TRANSMISIÓN DE LOS CONOCIMIENTOS PRODUCIDOS POR PROGRAMAS DE POSGRADO INTERDISCIPLINARIOS}

\section{RAFAELA WILLE DE AGUIAR}

Mestrado no Programa de Pós-Graduação em Gestão da Informação da Universidade Federal do Paraná

rafaela.wille@gmail.com.

\section{MARIA DO CARMO DUARTE FREITAS}

Doutorado em Engenharia de Produção e Sistemas pela Universidade Federal de Santa Catarina. Professora do Departamento de Ciência e Gestão da Informação e do Programa de Pós-Graduação em Gestão da Informação da Universidade Federal do Paraná 


\title{
Resumo
}

A pesquisa aborda a transmissão de conhecimentos realizada por Programas de Pós-Graduação da área Interdisciplinar e tem como objetivo identificar os meios de transmissão utilizados por eles. Para esse fim, aplicou-se um questionário com uma amostra não probabilística de 59 docentes membros de Programas de Pós-Graduação da Área Interdisciplinar e as respostas foram analisadas utilizando-se de estatística descritiva e análise de conteúdo. Identificou-se que os conhecimentos científicos são aqueles indicados pelos respondentes como de maior importância e de maior grau de transmissão. Ademais, oito meios de transmissão foram indicados por mais da metade dos respondentes como com grau de utilização "Alto" ou "Muito Alto" para pelo menos um dos públicos, são eles: "Revistas Científicas"; "Projetos de Pesquisa"; "Dissertações e Teses"; "Grupos de Estudos/Discussão"; "Sites Institucionais"; "Eventos Extensionistas"; "Conversas Formais"; e "Materiais Didáticos". Apesar disso, somente os dois primeiros meios são constantes em quatro dos públicos considerados ("Comunidade Acadêmica Docente", "Comunidade Acadêmica Discente", "Comunidade Científica", "Membros Internos ao PPG"), sendo que nos dois públicos restantes ("Mercado de Trabalho" e "Sociedade em geral") não foram identificados meios de transmissão que se sobressaíssem. Finalmente, considera-se, com base na amostra pesquisada, que existe fragilidade na transmissão dos conhecimentos para os públicos "Mercado de Trabalho" e "Sociedade em geral" e sugere-se que estudos futuros busquem aprofundar a compreensão de como a transmissão de conhecimentos para eles ocorre.

Palavras-chave: Programas de pós-graduação. Transmissão de conhecimentos. CAPES - Área Interdisciplinar.

\begin{abstract}
The research addresses the transmission of knowledge carried out by postgraduate programs in the Interdisciplinary Area and aims to identify the means of transmission used by them. For this purpose, a questionnaire was applied to a non-probabilistic sample of 59 faculty members of postgraduate programs in the Interdisciplinary Area and the responses were analyzed using descriptive statistics and content analysis. It was identified that the scientific knowledge was indicated by the respondents with the greatest importance and the highest degree of transmission. Furthermore, eight means of transmission were indicated by more than half of the respondents as having a "High" or "Very High" degree of use for at least one audience. They are: "Scientific Journals"; "Research project"; "Dissertations and Theses"; "Study/Discussion Groups"; "Institutional Sites"; "Extension Events"; "Formal Conversations"; and "Didactic Materials". Despite this, only the first two means are included in four of the audiences considered ("Academic Teaching Community", "Academic Student Community", "Scientific Community", "Members Internal to PPG"), and in the remaining two audiences ("Labor Market" and "Society in General") no outstanding means of transmission have been identified. Finally, it is considered, based on the researched sample, that there is a weakness in the transmission of knowledge to the publics "Labor Market" and "Society in General", and it is suggested that future studies seek to deepen the understanding of how knowledge transmission occurs to them.
\end{abstract}

Keywords: Postgraduate programs. Knowledge transmission. CAPES - Interdisciplinary Area.

\section{Resumen}

La investigación aborda la transmisión de conocimientos realizada por los Programas de Posgrado en el Área Interdisciplinaria y tiene como objetivo identificar los medios de transmisión utilizados por ellos. Para este propósito, se aplicó un cuestionario como una muestra no probabilística de 59 docentes miembros de programas de posgrado en el Área Interdisciplinaria y las respuestas se analizaron mediante estadísticas descriptivas y análisis de contenido. Se identificó que los conocimientos científicos son aquellos indicados por los encuestados como de mayor importancia y de mayor grado de transmisión. Además, ocho medios de transmisión fueron indicados por más de la mitad de los encuestados como

Revista Brasileira de Pós-graduação-RBPG, ISSN (on-line): 2358-2332.

Brasília, v.16, n. 36, jul./dez., 2020

Estudos 
teniendo un grado de uso "Alto" o "Muy Alto" para al menos uno de los públicos, son ellos: "Revistas Científicas"; "Proyectos de Investigación"; "Disertaciones y Tesis"; "Grupos de Estudios/Discusiones"; "Sitios Institucionales"; "Eventos Extensionistas"; "Conversaciones Formales"; y "Materiales Didácticos". A pesar de esto, solo los primeros dos medios son constantes en cuatro de los públicos considerados ("Comunidad Académica Docentes", "Comunidad Académica Discentes", "Comunidad científica", "Miembros internos de PPG"), y en los dos públicos restantes ("Mercado de Trabajo" y "Sociedad en general") no se han identificado medios de transmisión que se destacan. Finalmente, se considera, con base en la muestra investigada, que existe una debilidad en la transmisión de los conocimientos para los públicos "Mercado de Trabajo" y "Sociedad en general" y se sugiere que los estudios futuros busquen profundizar la comprensión de cómo se les transmite el conocimiento.

Palabras clave: Programas de posgrado. Transmisión de conocimiento. CAPES - Área Interdisciplinaria.

\section{INTRODUÇÃO}

Em meio a um cenário de tentativas de desmanche do ensino público, de desvalorização da ciência e da pesquisa brasileira torna-se importante que as universidades, em especial a pós-graduação, tenham o apoio da sociedade. Contudo, para que isso aconteça, é necessário ir além dos muros das instituições de educação superior para que as pessoas conheçam e compreendam o que é pesquisado (ISAAC, 2019).

Aliado a essa necessidade, existem também as determinações e diretrizes que orientam a educação superior (BRASIL, 1996). E, embora a educação superior e a pós-graduação apresentem diferenças conceituais, reconhece-se o relacionamento entre ambas conforme a Lei no 9.394 de 20 de dezembro de 1996, também conhecida como Lei de Diretrizes e Bases da Educação Nacional (LDBEN) (BRASIL, 1996).

Desta forma, entende-se que a educação superior abrange " $[\ldots]$ cursos e programas: I - cursos sequenciais por campo de saber [...]; II - de graduação [...]; III - de pós-graduação; [...] IV - de extensão" (BRASIL, 1996, Art. 44). Em outras palavras, ainda que a pós-graduação apresente diretrizes específicas, ela também se caracteriza como um ramo da educação superior. Esta, por sua vez, tem entre suas finalidades ações relacionadas à transmissão de conhecimentos e à comunicação da ciência, conforme observado no Artigo 43 da LDBEN (BRASIL, 1996).

No que tange às diretrizes específicas em relação ao Sistema Nacional de PósGraduação (SNPG), percebe-se que, historicamente, os Planos Nacionais de Pós-Graduação (PNPGs) abordam a pós-graduação brasileira como contribuinte ao desenvolvimento nacional e como produtora de conhecimentos (BRASIL, 2004, 2010). Apesar disso, por vezes, não se 
esclarece como os conhecimentos produzidos alcançariam ou alcançam as instâncias e pessoas necessárias para contribuir ao desenvolvimento brasileiro.

A preocupação com a transmissão dos conhecimentos torna-se mais explícita no $\mathrm{V}$ PNPG (BRASIL, 2004). E no VI PNPG essa transmissão de conhecimentos surge inclusive como um desafio a ser enfrentando pelo SNPG:

[...] por um lado necessitamos continuar ampliando a nossa base científica para podermos acompanhar os desenvolvimentos científicos que estão acontecendo no mundo. E, por outro lado, necessitamos fazer com que esses conhecimentos sejam colocados ao alcance dos cidadãos brasileiros de todos os recantos do país, especialmente as crianças e os jovens (BRASIL, 2010, p. 157, grifo nosso).

Dentro deste contexto, este artigo, oriundo de uma pesquisa de mestrado, insere-se como uma reflexão sobre a transmissão dos conhecimentos gerados em contextos universitários, com foco em Programas de Pós-Graduação (PPGs) interdisciplinares. E tem como objetivo mapear os meios de transmissão de conhecimentos utilizados por estes PPGs.

Restringiu-se a pesquisa a uma área de avaliação específica devido às limitações de tempo. Entre os motivos que resultaram na opção pela Área Interdisciplinar estão o fato dela ser aquela com o maior número de PPGs, 364 (dados da Plataforma Sucupira em 13/01/2020), divididos em quatro câmaras temáticas (I - Agrárias e Ambientais; II - Sociais e Humanidades; III - Engenharias, Gestão e Inovação; IV - Saúde e Biológicas) (BRASIL, 2017). Dessa maneira, ela caracteriza-se como uma área com um variado espectro de assuntos norteados pela premissa da interdisciplinaridade, que é

[...] a convergência de duas ou mais áreas do conhecimento, não pertencentes à mesma classe, que contribua para o avanço das fronteiras da ciência e tecnologia, transfira métodos de uma área para outra, gerando novos conhecimentos ou disciplinas e faça surgir um novo profissional com um perfil distinto dos existentes, com formação básica sólida e integradora (BRASIL, 2017, p. 1).

Além disso, a escolha por essa área deve-se também a uma aproximação pré-existente com ela, visto o PPG de vínculo das pesquisadoras ser da Área Interdisciplinar. Desta forma, existia-se experiência prévia com os critérios de avaliação que abordam, entre outros fatores, a produção de conhecimento, o impacto/inserção social e a visibilidade do PPG, e que podem influenciar a transmissão de conhecimentos. 


\section{A PÓS-GRADUAÇÃO BRASILEIRA}

A primeira LDBEN, de 1961, abordava a existência de cursos de pós-graduação no contexto da educação brasileira, contudo, sem caracterizar o que ou como seriam estes cursos (BRASIL, 1961). Em 1965, o Conselho Federal de Educação (CFE) publica o parecer no 977/65, que define o que é a pós-graduação no Brasil e qual a estrutura básica dos cursos que a compõem (BRASIL, 1965).

Definiu-se que a pós-graduação dividir-se-ia em lato sensu e stricto sensu. O primeiro referindo-se aos cursos de especialização com “[...] sentido eminentemente prático-profissional [...]” (BRASIL, 1965, sem paginação). E o segundo abrangendo os cursos de mestrado e doutorado com “[...] natureza acadêmica e de pesquisa [...]” (BRASIL, 1965, sem paginação).

Desta forma, a pós-graduação stricto sensu caracterizou-se como

o ciclo de cursos regulares em segmento à graduação, sistematicamente organizados, visando desenvolver e aprofundar a formação adquirida no âmbito da graduação e conduzindo à obtenção de grau acadêmico (BRASIL, 1965, sem paginação).

Ademais, o stricto sensu seria composto pelos cursos de mestrado e doutorado, autônomos entre si, ou seja, poderiam ser ofertados separadamente e um não seria pré-requisito para o outro (BRASIL, 1965). Ambos teriam em comum o diploma de graduação como prérequisito, sendo que cada programa de pós-graduação poderia exigir outros critérios para o ingresso dos estudantes (BRASIL, 1965).

O mestrado seria realizado em no mínimo um ano e o estudante cursaria um conjunto de disciplinas relacionadas à área de concentração do curso. Necessitaria, ainda, comprovar suficiência em uma língua estrangeira (BRASIL, 1965). Além disso, ele também participaria em atividades voltadas à realização de sua pesquisa e precisaria ser aprovado na defesa de sua dissertação (BRASIL, 1965).

Já o doutorado, de no mínimo dois anos, também contaria com: realização de disciplinas; atividades relacionadas à pesquisa; comprovação de suficiência em duas línguas estrangeiras; e necessidade de aprovação da defesa da tese (BRASIL, 1965). Além disso, o estudante de doutorado também poderia executar atividades relacionadas à prática docente (BRASIL, 1965).

Ademais, definiu-se que a pós-graduação poderia ser oferecida por qualquer tipo de instituição, não somente as universidades, desde que fossem cumpridos os requisitos mínimos 
exigidos (BRASIL, 1965). E o CFE seria o órgão responsável por avaliar esse cumprimento e autorizar a criação de novos cursos (BRASIL, 1965, 1968).

Em 1974, o decreto $\mathrm{n}^{\circ} 73.411$ determina a necessidade de elaboração do Plano Nacional de Pós-Graduação e de propostas para que a Política Nacional de Pós-Graduação fosse executada (BRASIL, 1974). Os cinco planos, abrangendo o período de 1974 até 2010 — ainda que não de maneira contínua — caracterizam-se como

protagonistas de cinco importantes etapas na história da pós-graduação brasileira: 1 - a capacitação dos docentes das universidades, formando o primeiro contingente de pesquisadores e especialistas em âmbito federal; 2 a preocupação com o desempenho e a qualidade; 3 - a integração da pesquisa desenvolvida na universidade com $\mathrm{o}$ setor produtivo, visando $\mathrm{o}$ desenvolvimento nacional; 4 - a flexibilização do modelo de pós-graduação, o aperfeiçoamento do sistema de avaliação e a ênfase na internacionalização; 5 - a introdução do princípio de indução estratégica, o combate às assimetrias e o impacto das atividades de pós-graduação no setor produtivo e na sociedade, resultando na incorporação da inovação no SNPG e na inclusão de parâmetros sociais no processo de avaliação (BRASIL, 2010, p. 16).

Esses PNPGs, de forma geral, abrangeram o SNPG enquanto produtor de conhecimentos e auxiliador no desenvolvimento brasileiro (BRASIL, 2004, 2010). O VI PNPG mantém essas percepções, e em um aspecto de continuidade ao colocado pelo V PNPG, retoma em seu escopo a importância da transmissão dos conhecimentos e da comunicação da ciência (BRASIL, 2010).

Desta forma, considera-se que a transmissão dos conhecimentos é um fator que deve ser considerado dentro de um contexto institucional externo e no contexto interno dos PPGs. Além disso, esse fator está relacionado tanto a um aspecto legal e institucional (BRASIL, 1996), quanto a um aspecto de responsabilidade social de alcançar as pessoas fora da academia (BRASIL, 2010; ISAAC, 2019).

\subsection{A UNIVERSIDADE, A PÓS-GRADUAÇÃO E A COMUNICAÇÃO DA CIÊNCIA}

A formação de recursos humanos qualificados, a geração e a transmissão de conhecimentos são importantes finalidades da educação superior (BRASIL, 1996; BORGES; ARAÚJO, 2001). Aliado a isso, no contexto universitário, no qual os participantes da pesquisa estão inseridos, encontra-se também a presença do tripé ensino, pesquisa e extensão (BRASIL, 1996; YABER; CHAVEZ; CSOBAN, 2018). 
Os conhecimentos, além de relacionados às finalidades da educação superior, podem ser compreendidos enquanto inseridos em produtos (artigos científicos, dissertações e teses, entre outros), sejam como resultado, sejam como insumos para a continuidade das atividades realizadas nas universidades (BRASIL, 1996; YABER; CHAVEZ; CSOBAN, 2018). E os PPGs inserem-se nessa estrutura enquanto unidades da instituição diretamente relacionadas às finalidades da educação superior e que têm como uma de suas características-chave a produção de conhecimentos (BRASIL, 2004, 2010).

Ao mesmo tempo, a inserção dos PPGs no contexto universitário torna-os participantes no tripé ensino, pesquisa e extensão. E considera-se que isto, em conjunto com o colocado pelo VI PNPG (BRASIL, 2010), reforça a necessidade dos PPGs não somente produzirem conhecimentos, mas de atuarem para garantir que esses conhecimentos sejam transmitidos para pessoas dentro e fora dos muros acadêmicos, ou seja, que pesquisadores, estudantes e outras parcelas da população possam conhecer e usufruir do que é gerado nos PPGs.

Essa saída dos muros acadêmicos pode ser compreendida dentro do contexto da Comunicação da Ciência (CC). Isso deve-se a ela ser, segundo Bryant (2003), “[...] o processo pelo qual a cultura científica e seu conhecimento incorporam-se à cultura comum" (BRYANT, 2003, p. 357, tradução nossa).

Burns, O’Connor e Stocklmayer (2003) agregam a definição de CC, e colocam que ela utiliza de diálogos, atividades, habilidades e meios para auxiliar na sua concretização. Ademais, no contexto individual, eles apresentam cinco objetivos para a CC: promover a consciência sobre a ciência (Awareness); o prazer que ela traz ao indivíduo (Enjoyment); incentivar o interesse das pessoas (Interest); auxiliar na formação de opiniões (Opinions); e desenvolver a compreensão que as pessoas têm sobre ela (Understanding) (BURNS; O'CONNOR; STOCKLMAYER, 2003).

Esses objetivos também estão presentes no contexto público, porém relacionados com a consciência pública da ciência (PAS - Public Awareness of Science), a compreensão pública da ciência (PUS - Public Understanding of Science), a literacia científica e a cultura científica (FIGURA 1) (BURNS; O’CONNOR; STOCKLMAYER, 2003). 
Figura 1 - Analogia da Montanha de Burns, O’Connor e Stocklmayer (2003).

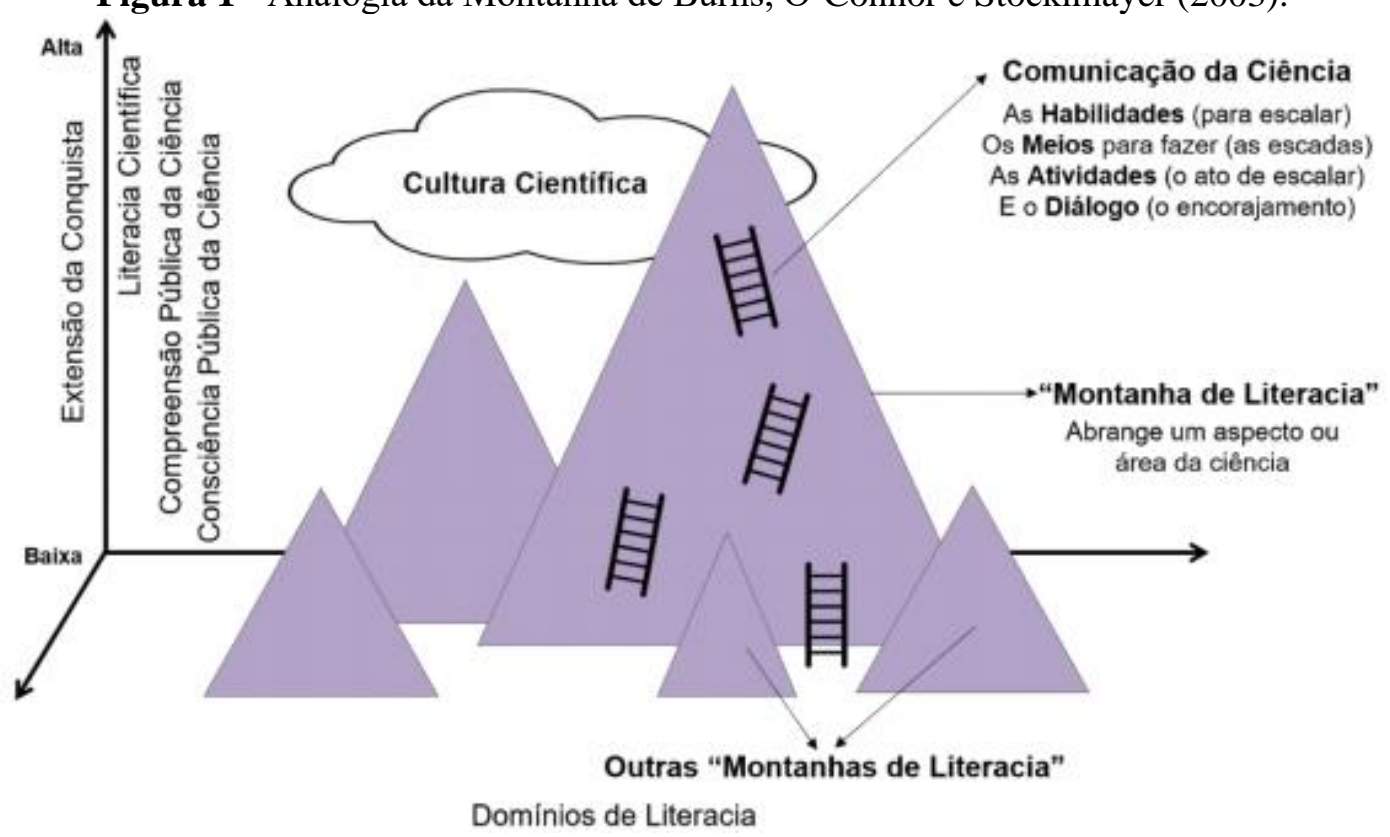

Fonte: Traduzido de Burns, O’Connor e Stocklmayer (2003)

A Comunicação da Ciência, apoiada pelas habilidades, meios, atividades e diálogo, funciona como uma escada entre o PAS, o PUS e a literacia científica, que é a conquista mais avançada, o estado máximo idealizado perante uma área da ciência (BURNS; O’CONNOR; STOCKLMAYER, 2003). Ressalta-se que existem diferentes "montanhas de literacia" a serem escaladas e que as "posições" das pessoas não são imutáveis, pois mesmo uma pessoa que alcançou o topo pode, ao longo do tempo, “descer" uma "montanha” (BURNS; O'CONNOR; STOCKLMAYER, 2003).

É importante reforçar também que o público não está necessariamente no pé de uma montanha e nem o cientista no topo (BURNS; O'CONNOR; STOCKLMAYER, 2003). De fato, "todas as pessoas estão entre uma planície e um pico" (BURNS; O’CONNOR; STOCKLMAYER, 2003, p. 193, tradução nossa).

A ideia de comunicação é que tanto o público quanto os cientistas participam, pois ambos têm uma mensagem a ser transmitida (BURNS; O'CONNOR; STOCKLMAYER, 2003). Essa compreensão da comunicação como um processo ativo assemelha-se ao modelo comunicacional de Osgood e Schramm (MARTINO, 2010), utilizado para a conceituação de transmissão de conhecimento adotada nesta pesquisa. 


\subsection{TRANSMISSÃO DE CONHECIMENTOS}

Entre as etapas ou atividades relacionadas ao conhecimento, identifica-se o processo no qual os conhecimentos de uma fonte alcançam um receptor. Não se identificou um consenso em qual é o termo (compartilhamento, disseminação, transferência, entre outros) utilizado para identificar dito processo.

Ao observar-se diferentes autores, como Szulanski (1996), Nonaka, Reinmoeller e Senoo (1998), Nonaka, Toyama e Konno (2000), Merlyn e Välikangas (1998), Hendriks (1999), Cummings (2003), Lafrenière et al. (2013) e Savolainen (2017), identificou-se que a comunicação ou a interação são fatores necessários para esse processo, independentemente do termo utilizado.

Martino (2010), ao apresentar o modelo comunicacional de Osgood e Schramm, aborda que esse modelo considera a comunicação enquanto um processo de interação, visto que tanto fonte quanto receptor participam ativamente e interagem entre si. Dessa forma, considerase que existem dois subprocessos de transmissão de mensagens: no primeiro, da fonte para o receptor; no segundo, os papéis invertem-se, visto que o receptor, ao transmitir uma resposta, torna-se também uma fonte, e a soma de ambos caracteriza a comunicação.

Em outras palavras, no contexto desta pesquisa, considerou-se a transmissão como um subprocesso unilateral da comunicação, que “[...] ocorre quando uma fonte transmite uma mensagem por algum meio para um receptor resultando em algum efeito, seja ele observável ou não" (AGUIAR, 2020, p. 44). E pela limitação da pesquisa considerou-se só o processo de transmissão que tem como fonte os PPGs Interdisciplinares.

Buscou-se na literatura artigos semelhantes de forma a identificar possíveis meios de transmissão do conhecimento. O Quadro 1 apresenta os meios e os respectivos autores. 
Quadro 1 - Possíveis meios de transmissão.

\begin{tabular}{|c|c|}
\hline Meios & Autores \\
\hline $\begin{array}{l}\text { - Confraternizações } \\
\text { - Visitas } \\
\text { - Reuniões formais } \\
\text { - Comunicação eletrônica } \\
\text { - Documentos formais } \\
\text { - Sistemas de gestão compartilhado } \\
\text { - Produtos e/ou serviço }\end{array}$ & Holanda, Francisco e Kovaleski (2009) \\
\hline $\begin{array}{l}\text { - Entrevistas } \\
\text { - Conversas } \\
\text { - Analogias } \\
\text { - Metáforas } \\
\text { - Treinamento e workshops } \\
\text { - Jornal } \\
\text { - Homepage do projeto } \\
\text { - Grupos de usuários (sites ) } \\
\text { - Visitas } \\
\text { - Materiais especializados } \\
\text { - Documentação } \\
\text { - Questionários, Simulações } \\
\text { - TI } \\
\text { - Help desk SAP }\end{array}$ & Mussi e Angeloni (2011) \\
\hline $\begin{array}{l}\text { - Redes sociais } \\
\text { - Twitter } \\
\text { - Foursquare } \\
\text { - Google Groups } \\
\text { - Redes sociais } \\
\text { - Sites } \\
\text { - Blogs } \\
\text { - Vimeo } \\
\text { - Youtube } \\
\text { - Salas de bate papo } \\
\text { - Listas de discussões } \\
\text { - Google Groups } \\
\text { - Slideshare } \\
\text { - Wikis } \\
\text { - RSS/ATOM }\end{array}$ & 更 \\
\hline - Publicação audiovisual de entrevistas em revista científica & Gallo (2011) \\
\hline - Portais institucionais & Bueno (2014) \\
\hline
\end{tabular}


AGUIAR, Rafaela Wille de; FREITAS, Maria do Carmo Duarte

"A transmissão dos conhecimentos produzidos por programas de pós-graduação interdisciplinares"

\begin{tabular}{|c|c|}
\hline Meios & Autores \\
\hline $\begin{array}{l}\text { - Blogs } \\
\text { - Site institucional } \\
\text { - Youtube } \\
\text { - Redes sociais } \\
\text { - Mensagens instantâneas (chats ) } \\
\text { - E-mail } \\
\text { - Seminários } \\
\text { - Grupos de estudo } \\
\text { - Capacitações e treinamentos }\end{array}$ & Nunes et al. (2015) \\
\hline $\begin{array}{l}\text { - Apresentação oral e palestra } \\
\text { - Trabalho publicado em anais } \\
\text { - Assessoria e consultoria } \\
\text { - Livro ou capítulo de livro } \\
\text { - Produtos, processos ou técnicas } \\
\text { - Relatório de pesquisa } \\
\text { - Sala de aula, material didático ou instrucional } \\
\text { - Artigo de periódico, livro ou capítulo de livro } \\
\text { - Projetos de pesquisa, extensão e tecnológicos } \\
\text { - Entrevistas, mesas-redondas, programas e comentários na mídia } \\
\text { - Trabalhos técnicos } \\
\text { - Inovação e patente }\end{array}$ & Perucchi e Mueller (2015) \\
\hline $\begin{array}{l}\text { - Trabalhos de conclusão de curso } \\
\text { - Estudos de caso }\end{array}$ & Periotto e Monteiro (2016) \\
\hline - Memória organizacional & Pereira, Silva e Pinto (2016) \\
\hline $\begin{array}{l}\text { - Produção de materiais } \\
\text { - Atividades práticas } \\
\text { - Palestras } \\
\text { - Visitas } \\
\text { - Apresentação de projetos } \\
\text { - Questionário }\end{array}$ & Oliveira et al . (2016) \\
\hline $\begin{array}{l}\text { - Patentes e royalties } \\
\text { - Colaboração pesquisador e indústria } \\
\text { - Pesquisas cooperativas } \\
\text { - Publicações em conjunto } \\
\text { - Aprendizado da equipe } \\
\text { - Geração de inovações }\end{array}$ & Queiroz, Silva e Almeida (2017) \\
\hline - Comunidade de Prática (CoP) & Lira, Araújo e Duarte (2017) \\
\hline $\begin{array}{l}\text { - Redes sociais } \\
\text { - Mensagens instantâneas } \\
\text { - Reuniões } \\
\text { - Comunidade de Prática (CoP) }\end{array}$ & Campos, Medeiros e Melo (2018) \\
\hline - Materiais escritos (artigos, informações oficiais e editais) & Fernandes et al. (2018) \\
\hline $\begin{array}{l}\text { - Apresentação } \\
\text { - Disponibilização de material } \\
\text { - Grupo de estudo } \\
\text { - Publicações de resumos e artigos } \\
\text { - Formações } \\
\text { - Mídias sociais }\end{array}$ & Duminelli, Ezequiel e Yamaguchi (2018) \\
\hline
\end{tabular}

Fonte: Aguiar (2020) com base em Holanda, Francisco e Kovaleski (2009), Mussi e Angeloni (2011),

Silva e Molina (2011), Gallo (2011), Bueno (2014), Nunes et al. (2015), Perucchi e Mueller (2015), Periotto e Monteiro (2016), Oliveira et al. (2016), Pereira, Silva e Pinto (2016), Queiroz, Silva 
Almeida (2017), Lira, Araújo e Duarte (2017), Campos, Medeiros e Melo (2018), Fernandes et al. (2018), Duminelli, Ezequiel e Yamaguchi (2018).

Esses meios auxiliaram na formulação do questionário que listou para os respondentes 23 meios de transmissão do conhecimento, apresentados na seção de resultados e discussão.

\section{METÓDOS}

Aplicou-se um questionário que resultou, após a limpeza dos dados, em uma amostra de 59 docentes membros de Programas de Pós-Graduação Interdisciplinares inseridos em universidades. O questionário, disponibilizado online pela plataforma LimeSurvey da Universidade Federal do Paraná, foi composto na íntegra por 30 questões. E o link para o questionário foi enviado para os e-mails, das secretarias ou coordenações, dos PPGs da Área Interdisciplinar que constavam em suas páginas web e no Sucupira.

A amostra caracteriza-se como não probabilística por conveniência ou acessibilidade, visto que nem todos os indivíduos da população puderam ser alcançados. Ainda que o fato de se tratar de uma amostra não-probabilística represente a impossibilidade de generalização dos resultados, considerou-se que, sendo a pesquisa exploratória, os dados obtidos contribuem para a reflexão sobre a transmissão dos conhecimentos gerados por PPGs da Área Interdisciplinar. E, devido a extensão do questionário, optou-se por apresentar neste artigo somente as questões diretamente relacionadas ao objetivo apresentado na Introdução (Quadro 2). 
Quadro 2-Questões sobre os meios de transmissão.

\begin{tabular}{|c|c|c|}
\hline ID & Questão & Tipo \\
\hline Q4 & $\begin{array}{l}\text { Indique quais os conhecimentos do PPGe classifique-os segundo a importância } \\
\text { que eles têm e o grau em a transmissão deles ocorre: }\end{array}$ & Fechada \\
\hline Q4.1 & $\begin{array}{l}\text { Caso tenha escolhido a opção "Nenhuma" para alguma das opções acima, por } \\
\text { favor, informe o porquê: }\end{array}$ & Aberta \\
\hline Q5 & $\begin{array}{l}\text { Classifique a transmis são do conhecimento para os diferentes públicos segundo } \\
\text { a importância que eles têm e o grau em a transmissão deles ocorre: }\end{array}$ & Fechada \\
\hline Q7.1 & $\begin{array}{l}\text { Classifique, segundo o grau de utilização, os meios usados pelo PPG para } \\
\text { transmitir conhecimentos para a Comunidade Acadêmica (Docentes) e } \\
\text { Comunidade Acadêmica (Discentes): }\end{array}$ & Fechada \\
\hline Q7.2 & $\begin{array}{l}\text { Classifique, segundo o grau de utilização, os meios usados pelo PPG para } \\
\text { transmitir conhecimentos para a Comunidade Científica e Mercado de Trabalho: }\end{array}$ & Fechada \\
\hline Q7.3 & $\begin{array}{l}\text { Classifique, segundo o grau de utilização, os meios usados pelo PPG para } \\
\text { transmitir conhecimentos Entre os membros do PPGe para a Sociedade em geral: }\end{array}$ & Fechada \\
\hline Q8.3 & Se desejar acrescente aqui outros meios/formas não listados. & Aberta \\
\hline Q9 & $\begin{array}{l}\text { Quais você considera as melhores e/ou mais importantes práticas de transmis são } \\
\text { do conhecimento realizadas no PPG? Por quê? }\end{array}$ & Aberta \\
\hline
\end{tabular}

Fonte: As autoras (2020).

No que tange às questões qualitativas, foram analisadas somente 58 respostas, visto um indivíduo ter respondido com uma única letra as questões abertas. E, visto que a Q4.1 e Q8.3 obtiveram poucas respostas, elas são apresentadas individualmente. Já para a Q9, utilizouse da Análise de Conteúdo, em específico da análise e categorização temática por acervo (BARDIN, 2016), apoiada pelo uso do Microsoft Excel e NVivo Pro.

Analisou-se as questões fechadas com apoio Microsoft Excel, por meio da estatística descritiva, responsável por “[...] descrever, analisar e interpretar os dados de uma população ou amostra" (FONSECA; MARTINS, 2010, p. 101)". E para possibilitar a verificação da Moda e Mediana normalizou-se todas as escalas de maneira crescente (1 até 5 ou 1 até 6 ).

\section{RESULTADOS E DISCUSSÃO}

Para distinguir os diferentes tipos de conhecimentos presentes nos PPGs utilizou-se como base o documento da avaliação da Área Interdisciplinar (BRASIL, 2017). Dito isso, apresentou-se como variáveis na Q4 os conhecimentos: Científicos (C); Didáticos (D); Instrumentais (I); Tecnológicos (T); e Administrativos (A). E considerou-se como obtendo alta importância aqueles conhecimentos em que o somatório de ocorrências nas categorias "Alta" ou "Muito Alta" foram superiores a 50\% do total de respondentes. O GRÁFICO 1 apresenta a distribuição de respostas. 
Gráfico 1 - Respostas sobre a transmissão - tipos de conhecimentos.

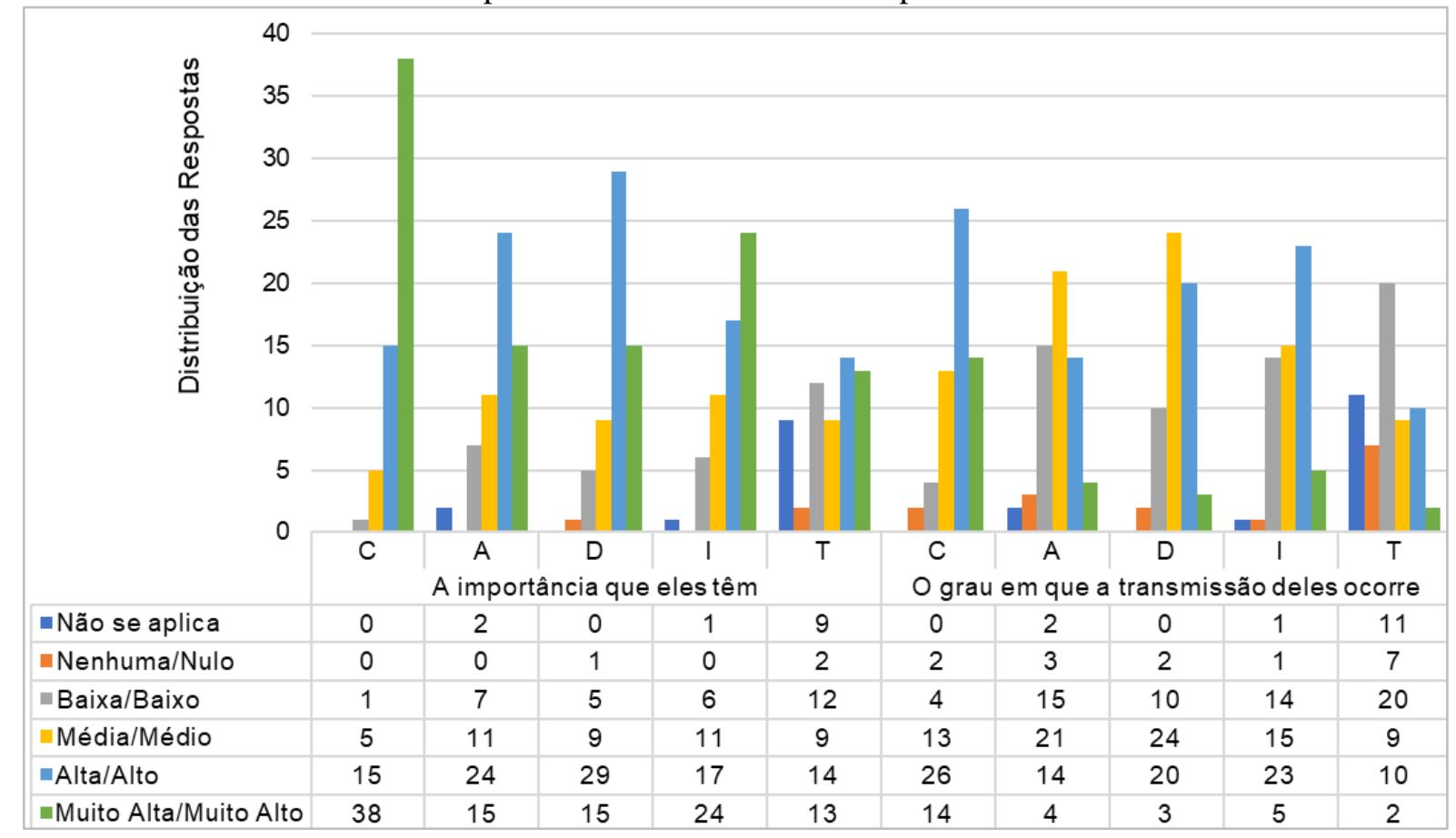

Fonte: As autoras (2020)

Neste caso, somente os conhecimentos tecnológicos não apresentaram alta importância. Ademais, dois respondentes avaliaram sua importância como "Nenhuma", comentando, na Q4.1, que esse tipo de conhecimento não é valorizado ou incentivado no PPG (Respondente 46) ou ele não está relacionado à área de atuação do PPG (Respondente 49).

Em outras palavras, identificou-se que, com exceção dos tecnológicos, todos os tipos listados (científicos, didáticos, instrumentais e administrativos) foram identificados pelos indivíduos como de alta importância. E, entre eles, os "Conhecimentos Científicos" foram aqueles com a maior quantidade de respostas, 53 (89,83\%), nas categorias "Alta" ou "Muito Alta”, seguidos pelos “Conhecimentos Didáticos” (44 respostas - 74,58\%).

Apesar disto, ao analisarem-se os dados, verificou-se que, de maneira geral, a avaliação do grau de transmissão dos tipos de conhecimentos foi inferior à da importância. E, utilizando-se o mesmo critério que na importância para avaliar um grau como alto (mais de $50 \%$ das respostas nas categorias “Alto" e "Muito Alto"), somente os conhecimentos científicos obtiveram um alto grau de transmissão, com 40 respostas $(67,80 \%)$ nas categorias citadas.

Essa diferença encontrada entre a importância e o grau de transmissão também ocorre ao questionar-se esses dois aspectos segundo os diferentes públicos: "Comunidade Acadêmica 
Docente" (CADo); "Comunidade Acadêmica Discente" (CADis); "Comunidade Científica" (CC); "Mercado de Trabalho" (MT); "Membros Internos ao PPG" (PPG); e "Sociedade em geral” (S). O Gráfico 2 apresenta a distribuição de respostas da Q5.

Gráfico 2 - Respostas sobre a transmissão - Públicos.

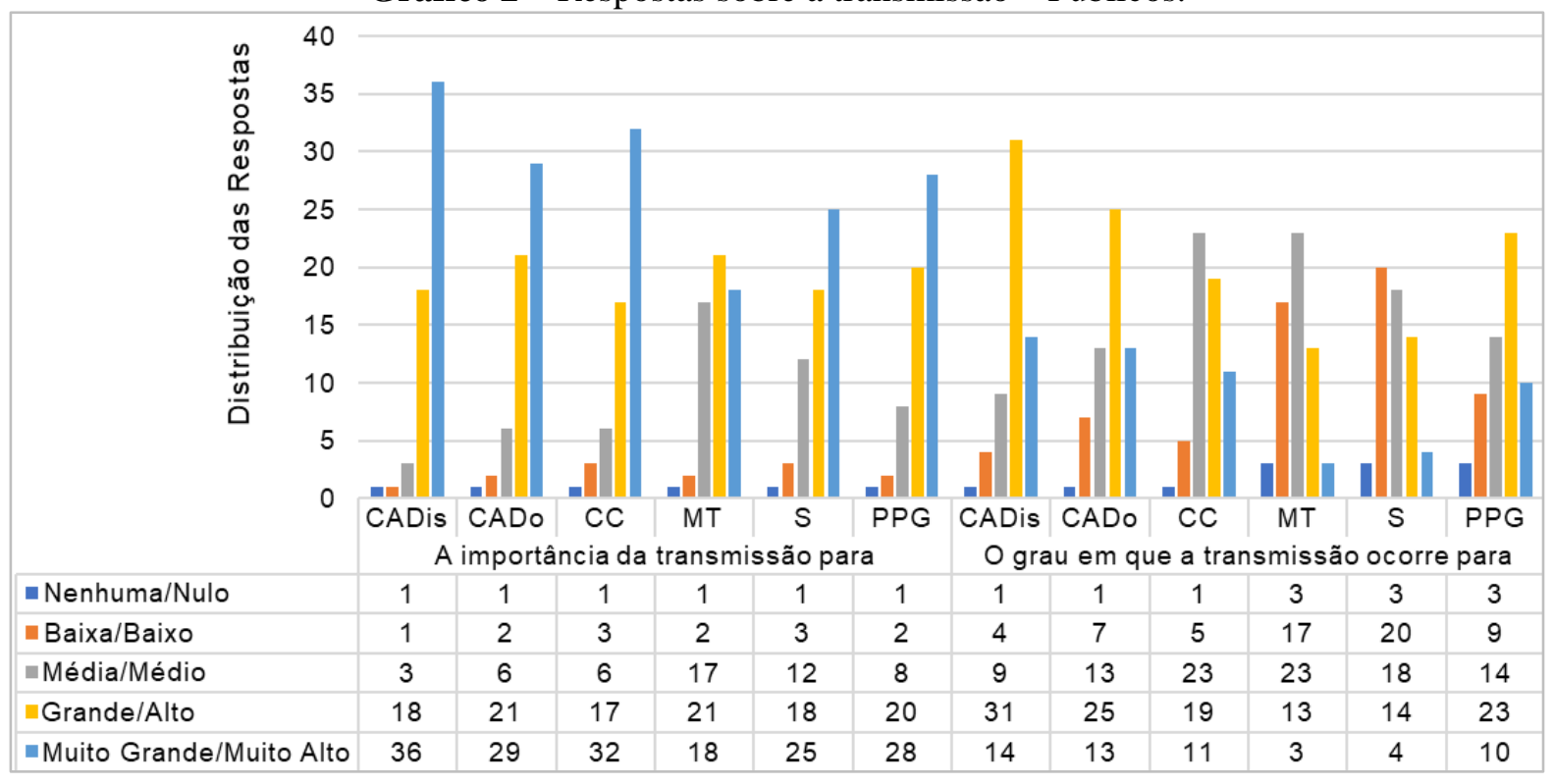

Fonte: As autoras (2020).

Assim como apresentado na questão Q4, considera-se como públicos de grande importância e/ou alto grau de transmissão aqueles que apresentaram mais de 50\% das respostas nas categorias "Grande/Alto" ou "Muito Grande/Muito Alto". Nesse caso, todos os públicos, conforme observado no GRÁFICO 2 apresentaram alta importância, com mais de 65\% das respostas como "Grande" ou "Muito Grande".

Apesar disso, proporcionalmente, o "Mercado de Trabalho" e a "Sociedade em geral" foram aqueles com os menores valores de importância, menos de $80 \%$ das respostas "Grande" ou "Muito Grande". Ademais, esses dois públicos são aqueles em que não se identificou um alto grau de transmissão.

Os quatro públicos restantes (CADis, CADo, CC e PPG) apresentaram alto grau de transmissão. E, entre eles, sobressaem-se a CADo e CADis, com mais de $60 \%$ das respostas referentes ao grau como "Alto" ou "Muito Alto".

A Q7 listou para os respondentes 23 meios de transmissão. Foram eles: "Revistas Científicas"; "Conversas Formais"; "Conversas Informais"; "Material Audiovisual Físico"; "Material Audiovisual Digital"; "Redes Sociais Tradicionais"; "Redes Sociais Especializadas"; 
"Revistas/Jornais não científicos"; "Televisão/Rádio"; "Eventos Extensionistas"; "Eventos Técnicos/Tecnológicos”; "Eventos Científicos”; "Dissertações e Teses”; “Grupos de Pesquisa”; "Projetos de Pesquisa"; "Sites Institucionais"; "Grupos de Estudo/Discussão"; "Material Didático"; "Projetos de Extensão"; "Sala de Aula"; "Consultorias"; "Relatórios Técnicos"; e "Capacitações".

A Q7 também serviu como condicional para a Q7.1, Q 7.2 e Q7.3, que indagavam quais os meios de transmissão de conhecimentos utilizados para cada um dos públicos (CADis, CADo, CC, PPG, MT e S). Assim como nas questões anteriores, caracterizou-se como meios mais utilizados aqueles nos quais mais de $50 \%$ das respostas encontravam-se como "Utilizado" ou "Muito Utilizado" (Quadro 3).

Quadro 3 - Públicos nos quais identificou-se meios de transmissão com mais de 50\% das respostas como "UTILIZADO" ou "MUITO UTILIZADO"

\begin{tabular}{|c|c|c|c|c|c|c|c|c|c|c|}
\hline \multirow{3}{*}{ Escala } & \multicolumn{10}{|c|}{ Comunidade Acadêmica Docente } \\
\hline & \multicolumn{2}{|c|}{ Revistas Científicas } & \multicolumn{2}{|c|}{ Projetos de Pesquisa } & \multicolumn{2}{|c|}{ Conversas Formais } & \multicolumn{2}{|c|}{ Grupos de Estudo } & \multicolumn{2}{|c|}{ Dissertações/Teses } \\
\hline & Qtd. & Freq. & Qtd. & Freq. & Qtd. & Freq. & Qtd. & Freq. & Qtd. & Freq. \\
\hline Inutilizado & 11 & $18,64 \%$ & 8 & $13,56 \%$ & 13 & $22,03 \%$ & 6 & $10,17 \%$ & 27 & $45,76 \%$ \\
\hline Pouco Utilizado & 0 & $0 \%$ & 3 & $5,08 \%$ & 2 & $3,39 \%$ & 7 & $11,86 \%$ & 2 & $3,39 \%$ \\
\hline Mediamente Utilizado & 3 & $5,08 \%$ & 6 & $10,17 \%$ & 8 & $13,56 \%$ & 15 & $25,42 \%$ & 0 & $0 \%$ \\
\hline Utilizado & 15 & $25,42 \%$ & 13 & $22,03 \%$ & 20 & $33,90 \%$ & 18 & $30,51 \%$ & 7 & $11,86 \%$ \\
\hline Muito Utilizado & 30 & $50,85 \%$ & 29 & $49,15 \%$ & 16 & $27,12 \%$ & 13 & $22,03 \%$ & 23 & $38,98 \%$ \\
\hline Mediana & \multicolumn{2}{|c|}{5} & \multicolumn{2}{|c|}{4} & \multicolumn{2}{|c|}{4} & \multicolumn{2}{|c|}{4} & \multicolumn{2}{|c|}{4} \\
\hline \multirow[t]{2}{*}{ Moda } & \multicolumn{2}{|c|}{5} & \multicolumn{2}{|c|}{5} & \multicolumn{2}{|c|}{4} & \multicolumn{2}{|c|}{4} & \multicolumn{2}{|c|}{1} \\
\hline & \multicolumn{10}{|c|}{ Membros Internos ao PPG } \\
\hline \multirow{2}{*}{ Escala } & \multicolumn{2}{|c|}{ Revistas Científicas } & \multicolumn{2}{|c|}{ Projetos de Pesquisa } & \multicolumn{2}{|c|}{ Conversas Formais } & \multicolumn{2}{|c|}{ Sites Institucionais } & Eventos & nsionistas \\
\hline & Qtd. & Freq. & Qtd. & Freq. & Qtd. & Freq. & Qtd. & Freq. & Qtd. & Freq. \\
\hline Inutilizado & 11 & $18,64 \%$ & 8 & $13,56 \%$ & 13 & $22,03 \%$ & 16 & $27,12 \%$ & 6 & $10,17 \%$ \\
\hline Pouco Utilizado & 0 & $0,00 \%$ & 5 & $8,47 \%$ & 5 & $8,47 \%$ & 3 & $5,08 \%$ & 14 & $23,73 \%$ \\
\hline Mediamente Utilizado & 3 & $5,08 \%$ & 7 & $11,86 \%$ & 4 & $6,78 \%$ & 7 & $11,86 \%$ & 7 & $11,86 \%$ \\
\hline Utilizado & 16 & $27,12 \%$ & 14 & $23,73 \%$ & 19 & $32,20 \%$ & 14 & $23,73 \%$ & 20 & $33,90 \%$ \\
\hline Muito Utilizado & 29 & $49,15 \%$ & 25 & $42,37 \%$ & 18 & $30,51 \%$ & 19 & $32,20 \%$ & 12 & $20,34 \%$ \\
\hline Mediana & & & & & & & 4 & & & \\
\hline Moda & & & & & & & 5 & & & \\
\hline & & & Comunid & Científica & & & Comu & hidade Aca & dêmica D & nte \\
\hline Fscala & Revista & entíficas & Projetos & Pesquisa & Sites In & ucionais & Revistas C & entíficas & Projeto: & Pesquisa \\
\hline Escala & Qtd. & Freq. & Qtd. & Freq. & Qtd. & Freq. & Qtd. & Freq. & Qtd. & Freq. \\
\hline Inutilizado & 12 & $20,34 \%$ & 9 & $15,25 \%$ & 15 & $25,42 \%$ & 11 & $18,64 \%$ & 9 & $15,25 \%$ \\
\hline Pouco Utilizado & 1 & $1,69 \%$ & 3 & $5,08 \%$ & 4 & $6,78 \%$ & 2 & $3,39 \%$ & 3 & $5,08 \%$ \\
\hline Mediamente Utilizado & 3 & $5,08 \%$ & 6 & $10,17 \%$ & 10 & $16,95 \%$ & 6 & $10,17 \%$ & 9 & $15,25 \%$ \\
\hline Utilizado & 14 & $23,73 \%$ & 19 & $32,20 \%$ & 14 & $23,73 \%$ & 19 & $32,20 \%$ & 15 & $25,42 \%$ \\
\hline Muito Utilizado & 29 & $49,15 \%$ & 22 & $37,29 \%$ & 16 & $27,12 \%$ & 21 & $35,59 \%$ & 23 & $38,98 \%$ \\
\hline Mediana & & & & & & & 4 & & & \\
\hline Moda & & & & & & & 5 & & & \\
\hline & & & & nidade Aca & êmica D & ente & & & & \\
\hline & Mater & idático & Grupo & Estudo & Conver & Formais & Dissertaçõ & s/Teses & & \\
\hline Escala & Qtd. & Freq. & Qtd. & Freq. & Qtd. & Freq. & Qtd. & Freq. & & \\
\hline Inutilizado & 9 & $15,25 \%$ & 6 & $10,17 \%$ & 13 & $22,03 \%$ & 27 & $45,76 \%$ & & \\
\hline Pouco Utilizado & 9 & $15,25 \%$ & 8 & $13,56 \%$ & 3 & $5,08 \%$ & 1 & $1,69 \%$ & & \\
\hline Mediamente Utilizado & 7 & $11,86 \%$ & 12 & $20,34 \%$ & 10 & $16,95 \%$ & 1 & $1,69 \%$ & & \\
\hline Utilizado & 10 & $16,95 \%$ & 20 & $33,90 \%$ & 19 & $32,20 \%$ & 8 & $13,56 \%$ & & \\
\hline Muito Utilizado & 24 & $40,68 \%$ & 13 & $22,03 \%$ & 14 & $23,73 \%$ & 22 & $37,29 \%$ & & \\
\hline Mediana & & & & & & & 4 & & & \\
\hline Moda & & & & & & & 1 & & & \\
\hline
\end{tabular}

Fonte: As autoras (2020) 
Percebe-se que de 23 meios, somente oito sobressaíram-se como de alta utilização, sendo que nenhum deles foi unânime para todos os públicos. Isso pode refletir a consciência de que os públicos têm necessidades diferentes e recebem e apreendem o conhecimento de formas variadas, sendo, portanto, necessário utilizar mais que um único meio de transmissão.

As "Revistas Científicas" e os "Projetos de Pesquisa" estão presentes nos quatro públicos (CADo, CADis, CC e PPG) que apresentaram meios com alto grau de utilização. Enquanto as "Conversas Formais" abrangem três deles, a CADo, a CADis e a CC.

Ambos os meios "Dissertações e Teses" e "Grupos de Estudos/Discussão" abrangeram tanto a CADo quanto a CADis. Já os "Sites Institucionais" (CC), os "Eventos Extensionistas" (PPG) e os "Materiais Didáticos" (CADis) são utilizados em alto grau para transmitir conhecimentos para somente um dos públicos.

Considera-se também que a não identificação de meios de transmissão de conhecimentos com altos graus de utilização para o Mercado de Trabalho (Q7.2) e Sociedade (Q7.3) pode estar relacionada a Q5, na qual verificou-se que esses dois públicos em específico não apresentaram alto grau de transmissão.

Os meios menos utilizados, aqueles em que mais de $50 \%$ das respostas foram "Inutilizado", constam no QUADRO 4. E a Moda e a Mediana para cada um deles neste caso são iguais a 1 .

Quadro 4 - Meios em que se identificou mais de 50\% das respostas sobre utilização como "INUTILIZADO"

\begin{tabular}{|c|c|c|c|c|c|c|c|c|c|c|c|c|}
\hline & \multicolumn{2}{|c|}{ CADo } & \multicolumn{2}{|c|}{ CADis } & \multicolumn{2}{|c|}{ CC } & \multicolumn{2}{|c|}{ PPG } & \multicolumn{2}{|c|}{ MT } & \multicolumn{2}{|c|}{8} \\
\hline & Qtd. & Freq. & Qtd. & Freq. & Qtd. & Freq. & Qtd. & Freq. & Qtd. & Freq. & Qtd. & Freq. \\
\hline Audiovisual Digital & 31 & $52,54 \%$ & 31 & $52,54 \%$ & 32 & $54,24 \%$ & 31 & $52,54 \%$ & 33 & $55,93 \%$ & 33 & $55,93 \%$ \\
\hline Audiovisual Físico & 35 & $59,32 \%$ & 35 & $59,32 \%$ & 36 & $61,02 \%$ & 35 & $59,32 \%$ & 37 & $62,71 \%$ & 36 & $61,02 \%$ \\
\hline Capacitações & 34 & $57,63 \%$ & 34 & $57,63 \%$ & 35 & $59,32 \%$ & 34 & $57,63 \%$ & 36 & $61,02 \%$ & 35 & $59,32 \%$ \\
\hline Consultorias & 44 & $74,58 \%$ & 44 & $74,58 \%$ & 45 & $76,27 \%$ & 44 & $74,58 \%$ & 45 & $76,27 \%$ & 44 & $74,58 \%$ \\
\hline Conversas Informais & 34 & $57,63 \%$ & 34 & $57,63 \%$ & 38 & $64,41 \%$ & 33 & $55,93 \%$ & 38 & $64,41 \%$ & 35 & $59,32 \%$ \\
\hline Televisão/Rádio & 46 & $77,97 \%$ & 46 & $77,97 \%$ & 46 & $77,97 \%$ & 47 & $79,66 \%$ & 47 & $79,66 \%$ & 46 & $77,97 \%$ \\
\hline Eventos Técnicos/Tecnológicos & 32 & $54,24 \%$ & 32 & $54,24 \%$ & 31 & $52,54 \%$ & 32 & $54,24 \%$ & 34 & $57,63 \%$ & 33 & $55,93 \%$ \\
\hline Projetos de Extensão & 32 & $54,24 \%$ & 32 & $54,24 \%$ & 32 & $54,24 \%$ & 32 & $54,24 \%$ & 32 & $54,24 \%$ & 33 & $55,93 \%$ \\
\hline Redes Sociais Especializadas & 40 & $67,80 \%$ & 40 & $67,80 \%$ & 41 & $69,49 \%$ & 40 & $67,80 \%$ & 42 & $71,19 \%$ & 44 & $74,58 \%$ \\
\hline Redes Sociais Tradicionais & 37 & $62,71 \%$ & 37 & $62,71 \%$ & 35 & $59,32 \%$ & 36 & $61,02 \%$ & 35 & $59,32 \%$ & 36 & $61,02 \%$ \\
\hline Relatórios Técnicos & 35 & $59,32 \%$ & 35 & $59,32 \%$ & 36 & $61,02 \%$ & 35 & $59,32 \%$ & 37 & $62,71 \%$ & 39 & $66,10 \%$ \\
\hline Sala de Aula & 20 & $33,90 \%$ & 25 & $42,37 \%$ & 14 & $23,73 \%$ & 14 & $23,73 \%$ & 3 & $5,08 \%$ & 7 & $11,86 \%$ \\
\hline Grupos de Pesquisa & ---- & ---- & ---- & ---- & ---- & $-\cdots--$ & ---- & ---- & 31 & $52,54 \%$ & ---- & --.- \\
\hline
\end{tabular}

Fonte: As autoras (2020)

Revista Brasileira de Pós-graduação-RBPG, ISSN (on-line): 2358-2332.

Brasília, v.16, n. 36, jul./dez., 2020

Estudos 
Entre os meios com mais de 50\% das respostas como "Inutilizado" identificou-se que 11 de 12 são constantes entre todos os públicos (CADo, CADis, CC, MT, S e PPG). São eles: “Audiovisual Digital”; “Audiovisual Físico"; "Capacitações”; “Consultorias”; “Conversas Informais"; "Televisão/Rádio"; "Eventos Técnicos/Tecnológicos"; "Projetos de Extensão"; "Redes Sociais Especializadas"; "Redes Sociais Tradicionais"; "Relatórios Técnicos"; e "Sala de Aula". Já os "Grupos de Pesquisa" aparecem somente em relação ao Mercado de Trabalho.

A Q8.3 buscou identificar outros meios não listados como opção no questionário. Somente dois indivíduos a responderam citando os programas de rádio painel publicitários, outdoors, eventos acadêmicos e atividades de campo.

A Q9 buscou verificar quais as práticas eram consideradas como as melhores ou mais importantes para transmissão dos conhecimentos e o porquê dessa percepção. A matriz relacionando o ID das respostas e as categorias encontradas durante a análise constam no Quadro 5. Para fins de visualização não se apresentou as respostas na íntegra, porém estas podem ser observadas em Aguiar (2020). 
AGUIAR, Rafaela Wille de; FREITAS, Maria do Carmo Duarte

"A transmissão dos conhecimentos produzidos por programas de pós-graduação interdisciplinares"

Quadro 5 - Matriz de Categorias e Respostas.

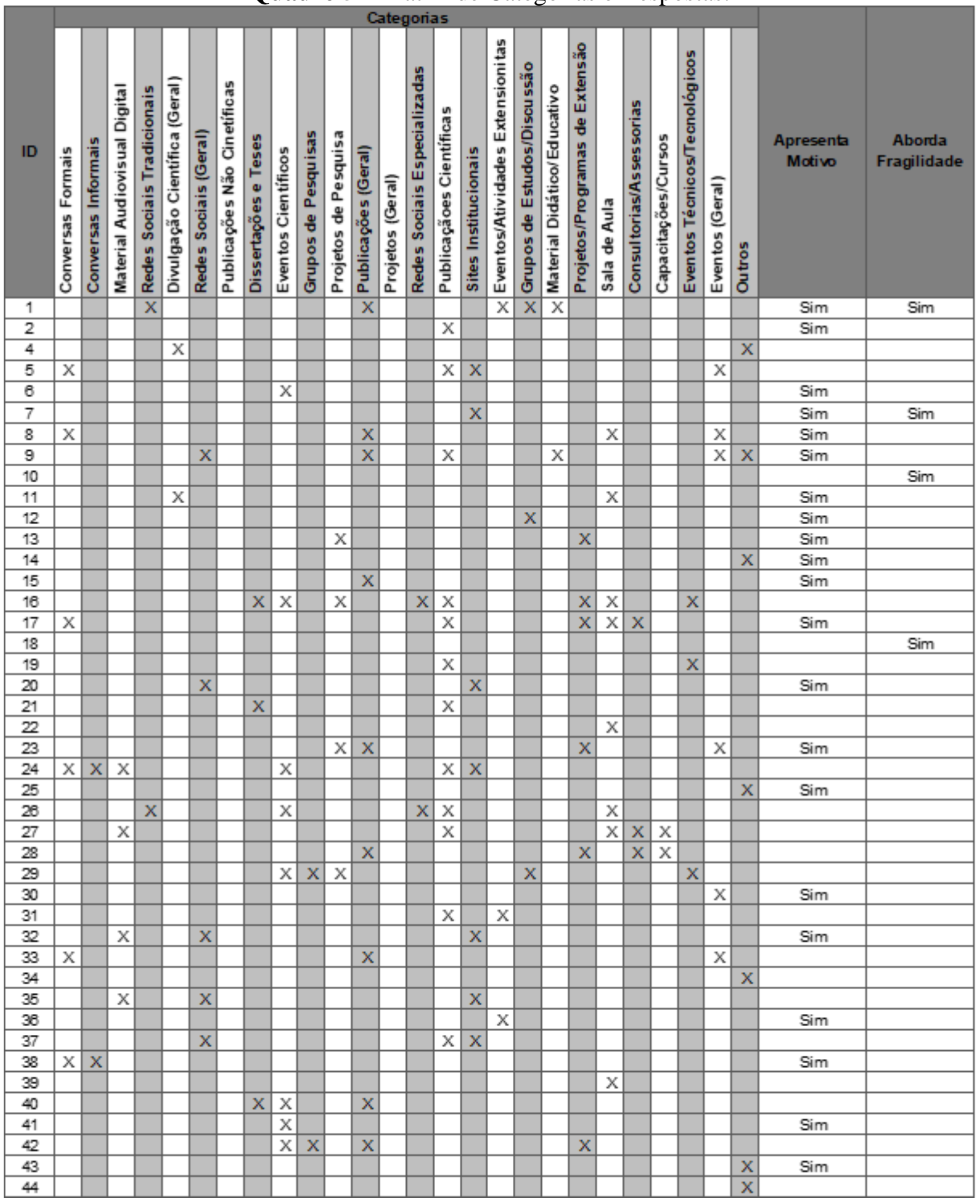

Revista Brasileira de Pós-graduação-RBPG, ISSN (on-line): 2358-2332.

Brasília, v.16, n. 36, jul./dez., 2020

Estudos 


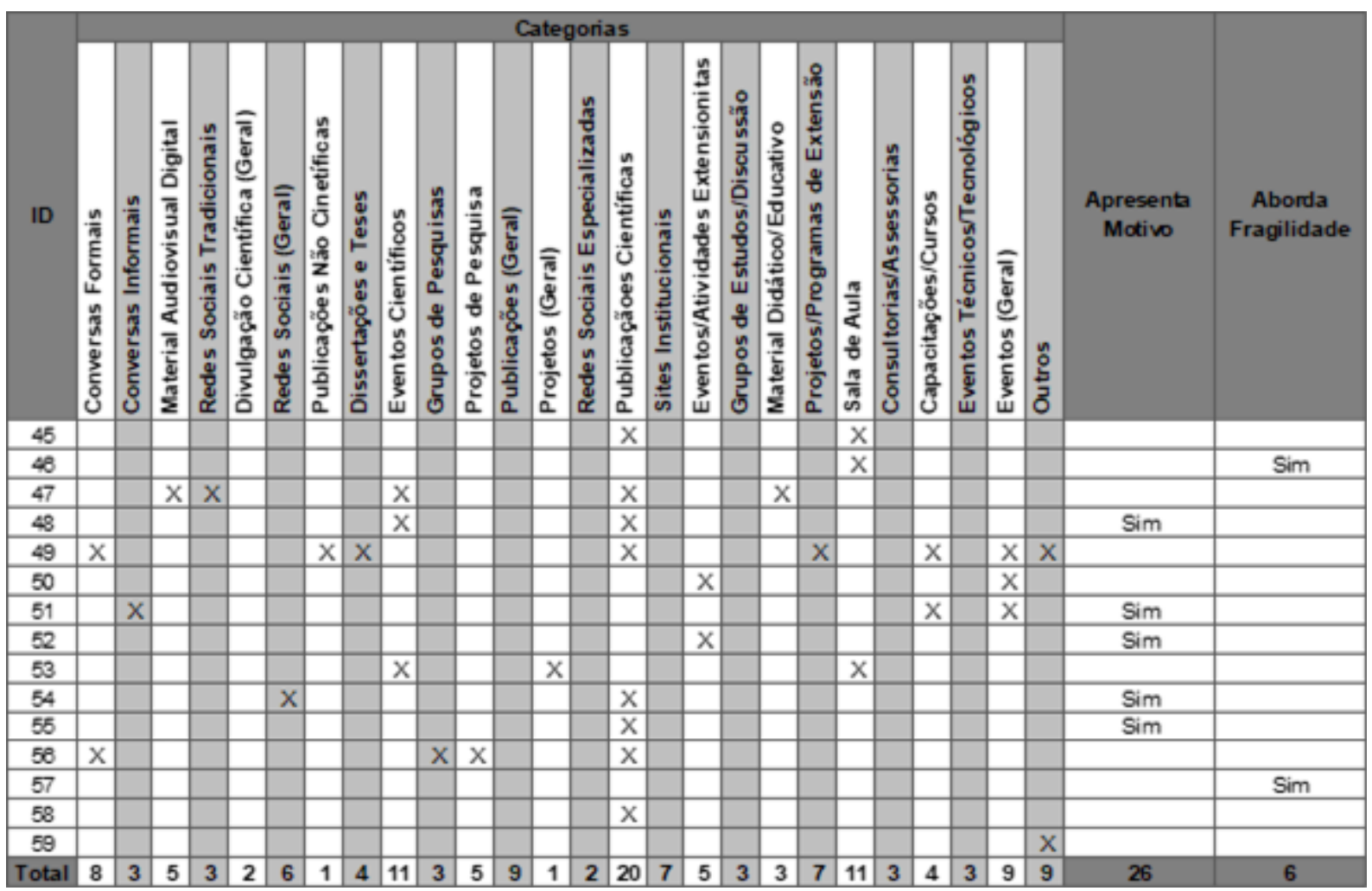

Fonte: As autoras (2020).

Nota-se que, embora a "Sala de Aula" conste entre os meios com mais distribuição de respostas em "Inutilizado", ao analisar-se a Q9 verificou-se que esse é o segundo meio, empatado com "Eventos Científicos", mais citado quando questionada quais as melhores/mais importantes práticas de transmissão, com 11 ocorrências. Sendo que o mais citado é "Publicações Científicas".

A Q9 verificou também o porquê de as práticas serem julgadas como melhores/mais importantes, sendo que somente 26 indivíduos indicaram em suas respostas trechos que foram categorizadas enquanto motivação. E a motivação de maior ocorrência (12 de 26) foi referente a abrangência, acesso e/ou visibilidade, embora não se tenha verificado um consenso sobre qual a prática seria a que mais tivesse essas características.

\section{CONSIDERAÇÕES FINAIS}

Entre a amostra pesquisada identificou-se que os "Conhecimentos Científicos" se sobressaem não só pela importância, mas também pelo grau de transmissão deles segundo os respondentes. A identificação da importância de todos os tipos de conhecimento, com exceção dos tecnológicos, pode representar a compreensão dos respondentes sobre o papel dos 
diferentes tipos de conhecimentos no contexto interdisciplinar. Ademais, o fato de somente os “Conhecimentos Científicos" apresentarem um alto grau de transmissão é um possível reflexo das limitações de tempo, carga de trabalho e formas de avaliação que influenciam a priorização desse tipo em contraponto a outros tipos de conhecimentos.

Essa priorização também explica só terem sido identificados meios com alta utilização (mais de 50\% das respostas como "Utilizado" ou "Muito Utilizado") para a CADo, CADis, CC e MT. E somente dois, "Revistas Científicas" e os "Projetos de Pesquisa", são constantes entre esses quatro públicos, um possível reflexo da valorização de meios já estabelecidos e formalmente avaliados.

Por fim, ressalta-se que, na amostra pesquisada, existe fragilidade na transmissão de conhecimentos para o "Mercado de Trabalho" e "Sociedade em geral", visto que, em ambos não existem alto grau de transmissão e nem meios que se sobressaiam. Considera-se que isto é um problema visto o papel do SNPG como contribuinte para o desenvolvimento nacional (BRASIL, 2004, 2010) e a colocação, pelo VI PNPG (BRASIL, 2010), do contato da pósgraduação com a sociedade em geral é um desafio a ser enfrentado.

Em outras palavras, julga-se necessário que o "Mercado de Trabalho" e "Sociedade em geral" sejam mais priorizados de forma a corroborar com o colocado no VI Plano Nacional de Pós-Graduação. Porém, reconhece-se que ações com esse fim não dependem somente do Programa de Pós-Graduação, mas também da aceitação e do incentivo por parte das instituições, das fontes de financiamento e da Coordenação de Aperfeiçoamento de Pessoal de Nível Superior, de forma a não sobrecarregar e prejudicar os envolvidos (professores, estudantes, entre outros).

Sugere-se que trabalhos futuros busquem aprofundar a compreensão sobre como a transmissão de conhecimentos ocorre para o "Mercado de Trabalho" e "Sociedade em geral". E se recomenda que se busque compreender não só como os PPGs transmitem o conhecimento, mas como esses dois públicos influenciam no processo, por exemplo, se existe uma busca ativa pelos conhecimentos produzidos.

\section{AGRADECIMENTOS}

O presente trabalho foi realizado com apoio da Coordenação de Aperfeiçoamento de Pessoal de Nível Superior - Brasil (CAPES) - Código de Financiamento 001. 


\section{REFERÊNCIAS}

AGUIAR, R. W. A transmissão dos conhecimentos produzidos pelos programas de pósgraduação interdisciplinares. 2020. Dissertação (Mestrado em Gestão da Informação) Universidade Federal do Paraná, Curitiba.

BARDIN, L. Análise de Conteúdo. São Paulo: Edições 70, 2016.

BORGES, D. F.; ARAÚJO, M. A. D. de. Uma experiência de planejamento estratégico em universidade: o caso do Centro de Ciências Sociais Aplicadas da UFRN. Revista de Administração Pública, v. 35, n. 4, p. 63-76, jul. 2001. Disponível em: http://bibliotecadigital.fgv.br/ojs/index.php/rap/article/view/6397. Acesso em: 18 out. 2020

BRASIL. Decreto n. 73.411, de 04 de janeiro de 1974. Institui o Conselho Nacional de PósGraduação e dá outras providências. Diário Oficial da União: Brasília, DF, 7 jan. 1974.

Lei n. 4.024, de 20 de dezembro de 1961. Fixa as Diretrizes e Bases da Educação Nacional. Diário Oficial da União: Brasília, DF, 27 dez. 1961.

Lei n. 5.540, de 28 de novembro de 1968. Fixa normas de organização e funcionamento do ensino superior e sua articulação com a escola média, e dá outras providências. Diário Oficial da União: Brasília, DF, 3 dez. 1968.

Lei n. 9.394, de 20 de dezembro de 1996. Estabelece as diretrizes e bases da educação nacional. Diário Oficial da União: Brasília, DF, 23 dez. 1996.

Ministério da Educação e Cultura. Conselho Federal de Educação. Parecer n. 977/65. 3 dez. 1965. Disponível em: https://www.capes.gov.br/images/stories/download/avaliacao/avaliacao-n/Parecer-9771965.pdf.

Ministério da Educação e Cultura. Coordenação de Aperfeiçoamento de Pessoal de Nível Superior. Plano Nacional de Pós-Graduação (PNPG): 2005 - 2010. Brasília, DF: MEC/CAPES, 2004.

. Ministério da Educação e Cultura. Coordenação de Aperfeiçoamento de Pessoal de Nível Superior. Plano Nacional de Pós-Graduação (PNPG) 2011 - 2020: Volume I. Brasília, DF: MEC/CAPES, 2010.

Ministério da Educação e Cultura. Coordenação de Aperfeiçoamento de Pessoal de Nível Superior. Relatório de Avaliação Interdisciplinar. [s.1.]: CAPES, 2017.

BRYANT, C. Does Australia need a more effective policy of science communication? International Journal for Parasitology, [s.1.], v. 33, n. 4, p. 357-361, abr. 2003. Disponível em: https://linkinghub.elsevier.com/retrieve/pii/S0020-7519(03)00004-3. Acesso em: 18 out. 2020. 
BUENO, W. C. A divulgação da produção científica no Brasil: a visibilidade da pesquisa nos portais das universidades Brasileiras. Ação Midiática: Estudos em Comunicação, Sociedade e Cultura, [Curitiba], n. 7, p.1-15, 2014. Disponível em:

https://revistas.ufpr.br/acaomidiatica/article/view/36340. Acesso em: 18 out. 2020.

BURNS, T. W.; O'CONNOR, D. J.; STOCKLMAYER, S. M. Science Communication: a contemporary definition. Public Understanding of Science, [s.1.], v. 12, n. 2, p. 183-202, abr. 2003. Disponível em: https://journals.sagepub.com/doi/abs/10.1177/09636625030122004. Acesso em: 18 out. 2020.

CAMPOS, I. M. S.; MEDEIROS, J. W. M.; MELO, M. S. M. Comunidade de prática (CoP) e aprendizagem organizacional no contexto da gestão de pessoas na Universidade Federal da Paraíba (UFPB). Navus: Revista de Gestão e Tecnologia, Florianópolis, v. 8, n. 2, p. 17-26, abr. 2018. Disponível em: http://navus.sc.senac.br/index.php/navus/article/view/634. Acesso em: 18 out. 2020.

CUMMINGS, J. Knowledge Sharing: a review of the literature. Washington: World Bank Operations Evaluation Department, 2003. Disponível em:

https://ieg.worldbankgroup.org/reports/knowledge-sharing-review-literature. Acesso em: 18 out. 2020.

DUMINELLI, M. V.; EZEQUIEL, K. B. O.; YAMAGUCHI, C. K. Perspectivas do compartilhamento do conhecimento entre os docentes para viabilizar a metodologia ativa. Visão, Caçador, v. 7, n. 2, p.20-32, jul. 2018. Disponível em: https://periodicos.uniarp.edu.br/index.php/visao/article/view/1331. Acesso em: 18 out. 2020.

FERNANDES, A. M. et al. Grupos de pesquisa: dinâmica do compartilhamento de conhecimento. Perspectivas em Gestão \& Conhecimento, João Pessoa, v. 8, n. 2, p. 107125, maio 2018. Disponível em:

https://periodicos.ufpb.br/ojs2/index.php/pgc/article/view/33902. Acesso em: 18 out. 2020.

FONSECA, J. S.; MARTINS, G. A. Estatística descritiva. In: Curso de estatística. São Paulo: Atlas, 2010. p. 101-165.

GALLO, S. L. Contradições na divulgação de conhecimento científico e cultural. Linguagem em (dis)curso, Tubarão, v. 11, n. 3, p.665-688, set., 2011. Disponível em: http://www.portaldeperiodicos.unisul.br/index.php/Linguagem_Discurso/article/view/826. Acesso em: 18 out. 2020.

HENDRIKS, P. Why share knowledge? the influence of ICT on the motivation for knowledge sharing. Knowledge and Process Management, [s.1.], v. 6, n. 2, p. 91-100, 1999. Disponível em: https://onlinelibrary.wiley.com/doi/epdf/10.1002/\%28SICI\%291099$1441 \% 28199906 \% 296 \% 3 \mathrm{~A} 2 \% 3 \mathrm{C} 91 \% 3 \mathrm{~A} \% 3 \mathrm{AAID}-\mathrm{KPM} 54 \% 3 \mathrm{E} 3.0 . \mathrm{CO} \% 3 \mathrm{~B} 2-\mathrm{M}$. Acesso em: 18 out. 2020.

HOLANDA, L. M. C.; FRANCISCO, A. C.; KOVALESKI, J. L. A percepção dos alunos do mestrado em engenharia de produção sobre a existência de ambientes de criação do conhecimento. Ciência da Informação, Brasília, v. 38, n. 2, p. 96-109, ago. 2009. Disponível 
em: http://www.scielo.br/scielo.php?script=sci_arttext\&pid=S0100-19652009000200008. Acesso em: 18 out. 2020.

ISAAC. R.; C. B. O futuro da universidade pública e da ciência no Brasil - 1/5. São Paulo: Universidade de São Paulo, 2019. 1 vídeo (45 min.). Disponível em:

https://www.youtube.com/watch?v=-TZ2kKQ5YXk. Acesso em: 18 out. 2020.

LAFRENIÈRE, D. et al. Knowledge dissemination interventions. Sage Open, [s.1.], v. 3, n. 3, p. 1-14, ago. 2013. Disponível em:

https://journals.sagepub.com/doi/full/10.1177/2158244013498242. Acesso em: 18 out. 2020.

LIRA, S. L.; ARAÚJO, W. J.; DUARTE, E. N. Cenários prospectivos para implantação de comunidades de prática em unidades de contabilidade em universidades públicas.

Perspectivas em Gestão \& Conhecimento, João Pessoa, v. 7, n. 1, p. 170-190, jan. 2017. Disponível em: https://periodicos.ufpb.br/index.php/pgc/article/view/33457. Acesso em: 18 out. 2020.

MARTINO, L. M. S. Teoria da comunicação: ideias, conceitos e métodos. Petrópolis: Vozes, 2010.

MERLYN, P. R.; VÄLIKANGAS, L. From information technology to knowledgetechnology: taking the user into consideration. Journal of Knowledge Management, [s.1.], v. 2, n. 2, p. 28-35, dez. 1998. Disponível em:

https://www.emerald.com/insight/content/doi/10.1108/13673279810249431/full/html. Acesso em: 18 out. 2020 .

MUSSI, C. C.; ANGELONI, M. T. Meios de compartilhamento do conhecimento no contexto de projetos de tecnologia da informação. Revista Eletrônica de Estratégia \& Negócios, Florianópolis, v. 4, n. 2, p. 30-60, dez. 2011. Disponível em: http://www.portaldeperiodicos.unisul.br/index.php/EeN/article/view/713. Acesso em: 18 out. 2020.

NONAKA, I.; REINMOELLER, P.; SENOO, D. The 'ART' of knowledge: systems to capitalize on market knowledge. European Management Journal, [s.1.], v. 16, n. 6, p. 673684, dez. 1998. Disponível em:

https://www.sciencedirect.com/science/article/abs/pii/S0263237398000449. Acesso em: 18 out. 2020.

NONAKA, I.; TOYAMA, R.; KONNO, N. SECI, Ba and Leadership: a unified model of dynamic knowledge creation. Long Range Planning, [s.1.], v. 33, n. 1, p. 5-34, fev. 2000. Disponível em: https://www.sciencedirect.com/science/article/abs/pii/S0024630199001156. Acesso em: 18 out. 2020.

NUNES, C. et al. Compartilhamento de conhecimento: os meios utilizados no contexto da educação a distância. Revista Gestão Universitária na América Latina, Florianópolis, v. 8, n. 1, p. 68-85, jan. 2015. Disponível em: https://periodicos.ufsc.br/index.php/gual/article/view/1983-4535.2015v8n1p68. Acesso em: 18 out. 2020. 
OLIVEIRA, A. C. et al. Popularização de conceitos e tecnologias de geração de energia com fontes renováveis em escolas de ensino médio de Itabira - MG. Revista Brasileira de Extensão Universitária, [s.1.], v. 7, n. 1, p. 59-64, jun. 2016. Disponível em: https://periodicos.uffs.edu.br/index.php/RBEU/article/view/3107. Acesso em: 18 out. 2020.

PEREIRA, M. O. F.; SILVA, H. F. N.; PINTO, J. S. P. A Memória organizacional nos processos de gestão do conhecimento: um estudo na Universidade Federal do Paraná. Informação \& Informação, Londrina, v. 21, n. 1, p. 348-374, jun. 2016. Disponível em: http://www.uel.br/revistas/uel/index.php/informacao/article/view/18253. Acesso em: 18 out. 2020.

PERIOTTO, T. R. C.; MONTEIRO, J. Gestão da produção intelectual para disseminação do conhecimento. Caderno de Administração, [Maringá], v. 24, n. 1, p. 53-65, out. 2016. Disponível em: http://www.periodicos.uem.br/ojs/index.php/CadAdm/article/view/30742. Acesso em: 18 out. 2020.

PERUCCHI, V.; MUELLER, S. P. M. Características das atividades de pesquisa dos professores dos Institutos Federais de Educação, Ciência e Tecnologia. Encontros Bibli, [s.1.], v. 20, n. 44, p. 73-88, set. 2015. Disponível em:

https://repositorio.unb.br/bitstream/10482/18943/1/ARTIGO_CaracteristicasAtividadesPesqui sa.pdf. Acesso em: 18 out. 2020.

QUEIROZ, F. C. B. P.; SILVA, H. F. N.; ALMEIDA, P. H. Determinantes do compartilhamento do conhecimento visando a cooperação internacional em ciência e tecnologia no Brasil. Perspectivas em Ciência da Informação, [s.l.], v. 22, n. 1, p. 133-150, mar. 2017. Disponível em: http://www.scielo.br/scielo.php?pid=S1413-

99362017000100133\&script=sci_abstract\&tlng=pt. Acesso em: 18 out. 2020.

SAVOLAINEN, R. Information sharing and knowledge sharing as communicative activities. Information Research, Borås, v. 22, n. 3, p. 1-20, set. 2017. Disponível em: http://informationr.net/ir/22-3/paper767.html. Acesso em: 18 out. 2020.

SILVA, M.; MOLINA, L. G. Adesão dos docentes universitários aos recursos da web 2.0 para disseminação e compartilhamento da informação e do conhecimento. Semina: Ciências Sociais e Humanas, Londrina, v. 32, n. 1, p. 65-76, jul. 2011. Disponível em: http://www.uel.br/revistas/uel/index.php/seminasoc/article/view/11502. Acesso em: 18 out. 2020.

SZULANSKI, G. Exploring internal stickiness: impediments to the transfer of best practice within the firm. Strategic Management Journal, [s.1.], v. 17, p. 27-43, 1996. Disponível em: https://onlinelibrary.wiley.com/doi/epdf/10.1002/smj.4250171105. Acesso em: 18 out. 2020.

YABER, G.; CHAVEZ, A.; CSOBAN, E. Modelo de gobernanza, liderazgo y gestión en instituciones de educación superior aplicado a la innovación curricular. Revista Academia \& Negócios, v. 4, n. 1, p. 53-64, jul. 2018. Disponível em: https://papers.ssrn.com/sol3/papers.cfm?abstract_id=3217115. Acesso em: 18 out. 2020. 